\begin{tabular}{|c|c|c|}
\hline Beitr. Ent. & Keltern & ISSN 0005 - 805X \\
\hline $54(2004) 1$ & S. 3-30 & 28.05 .2004 \\
\hline
\end{tabular}

\title{
The Heterotricha group in New Zealand
}

\section{(Diptera: Sciaroidea)}

With 30 figures

\section{MATHIAS JASCHHOF}

\section{Zusammenfassung}

Die Heterotricha-Gruppe sensu CHANDLER ist in Neusceland mit fünf Arten vertreten. Neben Anisotricha novaezealandiae (TONNOIR) sind dies Anisotricha similis sp. n. sowie die einer neuen Gattung, Insulatricha gen. n., zugeordneten Arten I. catrinae sp. n., I. chandleri sp. n. und I. bippaisp. n. Neuseeland erweist sich damit als eit rezentes Verbreitungszentrum für die Heterotricha-Gruppe. Sowohl Anisotricha als auch Insulatricha gehören zum Kern der möglicherweise nicht monophyletischen Gruppe, stehen aber in keinem SchwestergruppenVerhältnis. Die nächste Verwandtschaft von Insulatricha ist mit der Gattung Cbiletricha CHANDLER in der südlichen Neotropis zu finden, während die Schwestergruppe von Anisotricha zunächst nicht erkennbar ist.

\section{Summary}

The Heterotrichagroup sensu CHANDLER has five species in New Zealand. Apart from Anisotricha nonerealandiae (TONNOIR), these are Anisotricha similis sp. n. and, classified in a new genus, Insulatricha gen. n., the species I. catrinae sp. n., I. chandleri sp. n. and I. bippai sp. n. This makes New Zealand a recent distribution centre of the Heterotricha group. Both Anisotricha and Iisulatricha belong to the core of the possibly not monophyletic group, but are not sister taxa. The genus Insulatricha appears to be most closely related to the genus Chiletricha CHANDLER distributed it the southern Neotropics, while the closer relationship of Anisotricha remains unresolved for the time being.

\section{Keywords}

Diptera, Sciaroidea, Heterotricha group, taxonomy, new genus, new species, New Zealand

\section{Introduction}

The Heterotricha group has recently been subject of a comprehensive review by CHANDLER (2002). According to this review, 17 living species classified in nine genera occur in all biogeographic regions of the world except the Nearctic, and three species are known from Eocene amber. CHANDLER (2002) excludes from the Heterotrichagroup Pterogymns elongata FREEMAN, 1951 - a view followed here - and further proposes the inclusion of Mangas exilis KovALEV, 1986 - a suggestion rejected here. CHANDLER (2002) states that there is nothing to indicate that $M$. exilis was not allied to Heterotricha; on the other hand, indication that $M$. exilis, only fragmentary known from a Cretaceous amber fossil, actually belongs to this group appears very weak. 
The presence of the Heterotricha group in New Zealand was first noticed in the extensive work on the country's fungus gnats by TONNOIR \& EDWARDS (1927). The only species hitherto known, Heterotricha novaezealandiae TONNOIR, has recently become type of the monotypic genus Anisotricha CHANDLER, 2002. In the course of a study still in progress on various groups of the Sciaroidea in New Zealand (JASCHHOF \& DIDHAM, 2002; J ASCHHOF \& HIPPA, 2002; JASCHHOF \& JASCHHOF, 2003), the author became aware of the presence of several more Heterotricha-like species; these are described and discussed in the following. Initially, a further intention was to make a computerized parsimony analysis of the phylogenetic and biogeographic relationships of the world species belonging to the Ieterotricha group. However, soon it became apparent that such a venture would require the microscopic re-examination of almost all the species previously described, in particular the terminalia of their males. Apart from that, the author learned of the appearance of new I Heterotricha material from other parts of the world, including the first Australian species (COLLESS, in litt.; CHANDLER, in litt.), an African species close to the genus Rbynchobeterotricha FREEMAN, 1960 (HIPPA, in litt.) and females of the Japanese Sciaropota japonica CHANDLER, 2002 (KALLWEIT, pers. comm.). The study of such an extensive additional material was clearly beyond the manageable scope of an investigation that primarily aims to introduce and consider the affiliations of the New Zealand representatives.

As described in the following, New Zealand's remarkable sciaroid fauna includes a total of five Heterotricha-like species, two belonging to the genus Anisotricha and three classified in a new genus, Insulatricha gen. n. This makes New Zealand - besides southern South America and Africa - one of the recent distribution centres of the Heterotricha group and raises the number of named living species to a worldwide 21 for the time being. Clearly the previous idea that the Heterotricha-like flies are poor in species and extremely rarely found is outdated. Instead, the group appears to be quite diverse and regularly distributed in the temperate zones, particularly in those of the southern hemisphere. As already suggested by CHANDLER (2002), future research will certainly reveal the Heterotricha group, or parts of it, to deserve the status of a distinct family within the Sciaroidea.

\section{Material and methods}

Most of the specimens studied here were obtained from unsorted insect samples previously collected by New Zealand entomologists and deposited in various New Zealand institutions over the past almost 30 years (see the 'Material studied' sections of the species chapters). Additional specimens were collected by extensive Malaise trapping and sweepnetting in 2001-2002 in the course of a survey of various Sciaroidea led by the author. It should be noted that this study is based on 199 individuals in total, whereas only a handful of individuals of one species, Anisotricha novaezealandiae, was available for study to previous authors. Most of the studied specimens, including all types, are now deposited in the New Zealand Arthropod Collection, Auckland (NZAC).

Several individuals of each species, including all types, were mounted in Canada balsam on microscope slides in order to examine morphological details under a compound microscope. The mounting procedure followed that of JASCHHOF (1998) for lestremiine gall midges; however, before mounting the individuals were macerated in cold $10 \% \mathrm{KOH}$. Other individuals are stored in $70 \%$ ethanol. For light microscopic studies and the preparation of drawings the author used an Olympus BX50 microscope in combination 
with the U-DA drawing unit. Morphological terminology, if not otherwise stated, follows that of SÖLI (1997) for Mycetophilidae.

\section{Genus Insulatricha gen. n.}

Type species: Insulatricha bippai sp. n., described below.

\section{Description}

Head: Head capsule higher than long; its setation moderately long and undifferentiated. Postfrons slightly two-lobed, non-setose, with simple or slightly two-pointed frontal tubercle. Face large, non-setose. Clypeus smaller (especially narrower) than face, setose, fused with face along its upper margin. Antennae longer than body in males and shorter than body in females, upturned, inserted near midheight of head. Scape somewhat conical, a little larger than pedicel, with ventral setae. Pedicel subglobular, with a few setae along distal margin. Flagellum with 14 flagellomeres, first flagellomere longest, terminal flagellomere longer than penultimate; each flagellomere cylindrical, practically without neck, sevcral times as long as wide (basically longer in males than in females). In males, flagellum without microtrichia except a few on flagellomere 1 basally. Each flagellomere with an even cover of setac arising from membranous rings, these setae about 1.5 times as long as the diameter of the flagellomere or shorter; further with a few sensory spines. Flagellomeres $1(-3)$ dorsally with a few setae arising from sockets. In females, cover with microtrichia on flagellomere 1 more extensive, and setae arising from sockets longer, more numerous and sometimes present also on flagellomere 4 . With 3 ocelli at vertex, arranged in narrow triangle. Eyes reniform, separated at vertex for more than the width of the ocellar triangle; with fine, long interommatidal setulae. Mouthparts well developed, with short proboscis. Labrum beak-like, well sclerotized, non-setose or setose, fringed apically. Lingua with dense fringes apically. Maxillae with stipites separate and cardo absent; lacinia well developed or largely reduced. Maxillary palpus with 5 palpomeres, with the first palpomere ("presegment) smooth and non-setose. Palpomeres $2-5$ setose; palpomere 2 with 1 -2 wart-like sensillae distally; palpomeres (2-)3-4 with long hyaline sensory hairs, most numerous on palpomere 3; palpomere 3 thickest and 5 clearly longest. Labium with prementum present as pair of setose lobes; premental apodeme sclerotized and with paired processes of apparently species-specific outline. Labial palpus 2-segmented, labellum 1 smaller than 2 ; labellum 1 nonsetose; labellum 2 with numerous, partly spine-like setae.

Thorax: Postpronotum present as collar-like structure above neck. Antepronotum subtriangular, with a few setae. Episternum 1 with a few setae. Epimeron 1 small, subtriangular. Scutum in profile evenly arched to slight degree, with anterior parapsidal suture deep and median transverse suture not traceable. Vestiture of scutum consisting of irregular rows of long acrostichal, dorsocentral and lateral setae. Scutellum with short setae and pairs of long setae. Prescutoscutal suture deep. Prescutum distinct, strongly sclerotized. Mediotergite high, in profile almost straight to slightly arched. Postphragma well developed, i.e. extending into abdominal cavity. Mediotergite and laterotergites with distinct suture in between. Laterotergite large, not pronounced. Anepisternum subrectangular; separated from preepisternum 2 by distinct suture. Anepisternal cleft deep. Preepisternum 2 much larger than anepisternum, subtriangular ventrally. Anterior and posterior basalare distinct. Mid-pleural pit distinct. Epimeron 2 with deep cleft dorsally indicating a subdivision into upper anepimeron and lower katepimeron, the latter strongly narrowed 
ventrally. Metanotum very short, barely traceable. Episternum 3 subdivided by a cleft into small, indistinct upper portion (situated behind posterior spiracle) and large, subrectangular lower portion. Epimeron 3 very narrow. Openings of spiracles without striking features. Legs: Coxae longer than half the height of thorax. Coxae and femora with setae of moderate length. Tibial spurs 1:2:2, well developed. Fore tibia with well developed anteroapical depression bearing distal comb of setae; in males usually better developed than in females. Tibiae and tarsi covered with large trichia and short, somewhat scale-like setae, most densely on tarsomeres 2-4 and distal portion of tarsomeres 5, particularly underneath. Tarsomeres 1-5 gradually decreasing in length. Pretarsal claws small, curved, without teeth. Pulvilli well developed, about as long as claws. Empodia as long as claws or shorter. Wing: Long, i.e. more than two times as long as wide, but shorter than body. Calyptral area somewhat convex; anal area moderately developed. Membrane covered with setae, with setation less dense towards wing base. Venation: $C$ extending to apex of wing, ending at a point half way between apices of R5 and M1; Sc short, ending abruptly clearly before level of Rs; Rs oblique, slightly curved, much longer than ta; ta oblique; $\mathrm{R} 5$ with short faint portion proximally; $\mathrm{M} 1+2 \mathrm{stem}$ and fork subequal in length, fork clearly diverging; tb +mcu almost parallel to anterior wing margin, tb shorter or longer than mcu (varying even infraspecifically); CuP reaching to or going beyond half length of CuA2; A1 sometimes going beyond CuP but usually shorter (varying even infraspecifically); A2 barely traceable. $M$ absent, sometimes pretended to be present by a membrane fold. With setae present along wing margin and on Sc, R, R1 (dorsally and ventrally), sometimes Rs, R5 (dorsally and ventrally), $\mathrm{M} 1+2$ stem and fork (dorsally and ventrally), sometimes tb, sometimes mcu, CuA1 (dorsally and ventrally), CuA2, and A1. Pattern of sensory pores: R, 0-2; R1, 3-6; Rs, 1 2; R5, 1-2 proximally, 2-3 distally.

Abdomen: Tergites evenly covered with long setae. 'Tergite 1 and sternite 1 each subdivided into long anterior and short posterior plates with membranous portion in between. Tergite 1 shorter than 2 , and 7 longer than 8 . Sternite 1 usually non-setose. Sternite 2 with two membranous windows anteriorly separated by sclerotized bar bearing numerous sensory setulae. Membranous portions on sclerites 1 and 2 obviously creating a flexible zone enabling the abdomen to be bent behind segment 1 . Sternites 2-8 with long setae arranged in three irregular longitudinal rows. With six pairs of spiracles, one each on segments 2-7. Tergal plaques small, situated in a antero-lateral position on each of the tergites, with their pattern $0 / 1 / 1 / 1 / 1 / 1 / 1 / 0$.

Terminalia. Male. Sternite 9 present as distinct sclerite or intimately fused with gonocoxites. Gonocoxites almost separated ventrobasally or broadly joined, with setose lobe in gonocoxal section 3; gonocoxal apodemes connected by membranous or sclerotized transverse bridge. Gonostyli one- or two-lobed. Aedeagus with long sclerotized apodeme and usually complicated three-dimensional structure terminally. Parameres intimately fused to form a tegmen; tegmen with ventrolateral and distal lobes. Dorsal parameral apodemes well developed. Tergite 9 of varied shape but always bearing many short megasetae inside each distolaterally. Tergite 10 absent. Cerci rather short and broad. Hypoproct two-lobed, weak. Female. Mainly corresponding to basic pattern in Sciaroidea. With gonocoxites 8 extending caudally to or beyond tergite 10; gonapophyses 9 present as well sclerotized internal ribs that merge anteriorly to form a notum; tergite 10 rather short and indistinct; sternite 10 present as setose internal ribs that merge posteriorly; and both cerci well developed and subequal in size. With 2 sclerotized spermathecae. 
Diagnosis and discussion. Within the Heterotricha group, the genus Insulatricha is characterized by the combination of the following characters: the antennae are upturned and have a long flagellum (plesiomorphous conditions); the clypeus is unproduced (plesiomorphous); the meso- and metathoracic pleura are bare (plesiomorphous); the wing membrane and veins (including Sc) bear setae (plesiomorphous); Rs is oblique and longer than ta which is also oblique (plesiomorphous); the stem of $\mathrm{M} 1+2$ is long, i.e. subequal in length to the fork (apomorphous); the parameres are fused to form a tegmen (apomorphous); the male tergite 9 bears many short megasetae each distolaterally (apomorphous); the ovipositor is unmodified (plesiomorphous); and two sclerotized spermathecae are present (plesiomorphous). This definition of the genus is necessarily polythetic as no autapomorphous characters are recognizable of Insulatricha. A long stem of M1+2 is found throughout the Heterotricha group except in Heterotricha, Anisotricha and Sciarosoma; a tegmen is present in Cbiletricha, Anisotricha, Sciaropota and possibly others; and a tergite 9 modified in a similar way like that in Insulatricha is found in Chiletricha, Rbynchobeterotricha, and Kenyatricha.

Etymology. The name is composed of the Latin insula, for island, and a part of the genus name Heterotricha. Gender is feminine.

\section{Insulatricha hippai sp. n.}

(Figs 1-7)

\section{Description}

Male. Body size: $3.5-4.0 \mathrm{~mm}$.

Head (Fig. 1): Antenna with $4^{\text {th }}$ flagellomere 7 times as long as wide. Labrum non-setose. Maxillae with lacinia smooth and very short, sometimes not visible. Maxillary palpus segments (2-)3-4 with sensory hairs.

Thorax (Fig. 4): See generic description. Legs: Fore tibia with anteroapical depression (Fig. 2) bearing straight comb of 12-16 spine-like setae subequal in length, with distinct rounded upper rim in some distance from the comb, usually without setae between comb and rim. Wing (Fig. 5): Venation: tb shorter or longer than mcu, and A1 shorter than CuP.

Abdomen: Segment 8 more than half as long as segment 7 .

Terminalia: Gonocoxites (Fig. 6) ventrally almost separated from each other with sternite 9 in between, with setae of various lengths on its ventral and dorsal surfaces; with setose, rounded lobes in section 3 and bare, rounded lobes dorso-proximolaterally. Sternite 9 elongate, weakly sclerotized, non-setose or bearing 1-4 setae. Gonostyli (Fig. 6) usually turned inwards, broad proximally and wedge-shaped in distal half, with apex incised; with long setae on outer surfaces and very short, fine setae inside and terminally; basolateral apophysis large. Aedeagus (Fig. 3) with long sclerotized apodeme widened apically into weakly sclerotized head. Tegmen (Fig. 3) broad, with clear contours, distally with broadly rounded lip directed ventrally; ventral parameral apodemes short and sclerotized; dorsal parameral apodemes very long, well sclerotized and connected by weak transverse bridge. Tergite 9 (Fig. 7) almost completely subdivided medially, with long setae on its outer surface and many short, thorn-like, bi-pointed megasetae inside distally. Cerci (Fig. 7) narrowly 


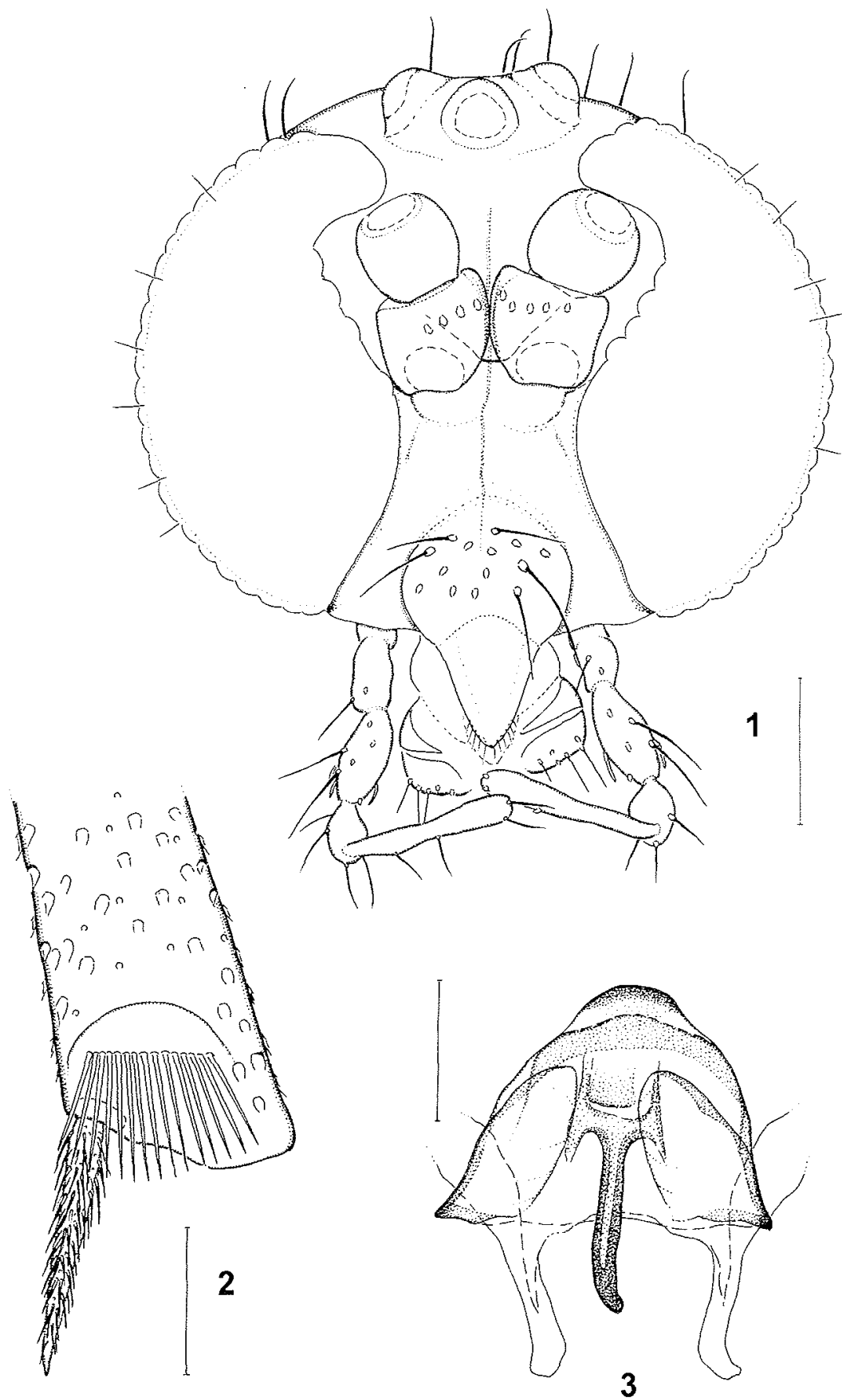

Figs 1-3: Insulatricha hippaisp. n., male. - 1: head, frontal view $(0.1 \mathrm{~mm})$; - 2: fore tibial anteroapical depression $(0.05 \mathrm{~mm})$; -3 : aedeagus and tegmen $(0.05 \mathrm{~mm}) .1$ and 3 : specimen from Lake Daniells Track; 2: paratype. (In parentheses: length of scale bar.). 


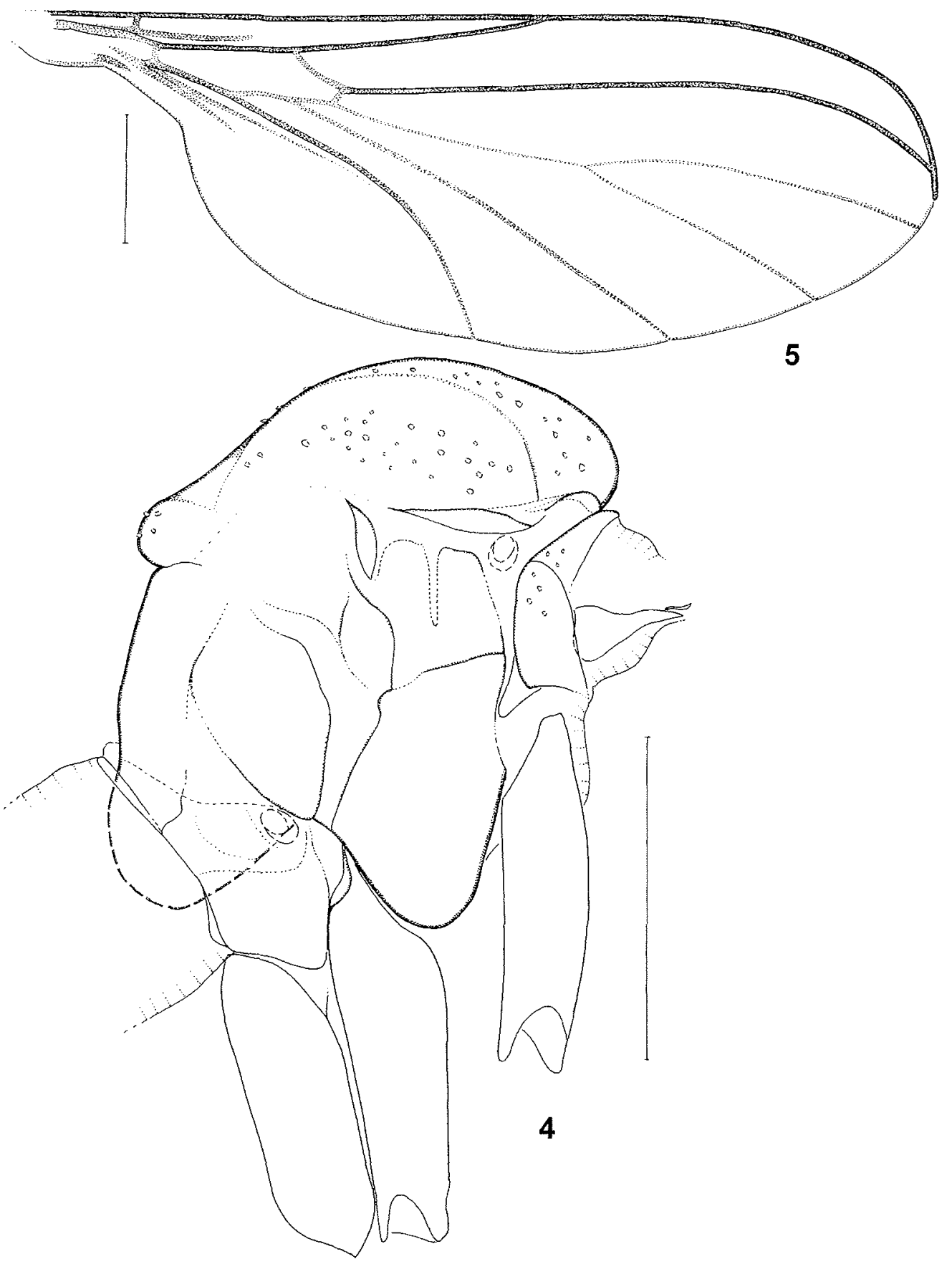

Figs 4, 5: Insulatricha bippai sp. 1n., male. - 4: thorax, lateral view $(0.5 \mathrm{~mm})$; - 5: wing, setae omitted $(0.5$ mm). 4: specimen from St Arnaud; 5: paratype. (In parentheses: length of scale bar.) 


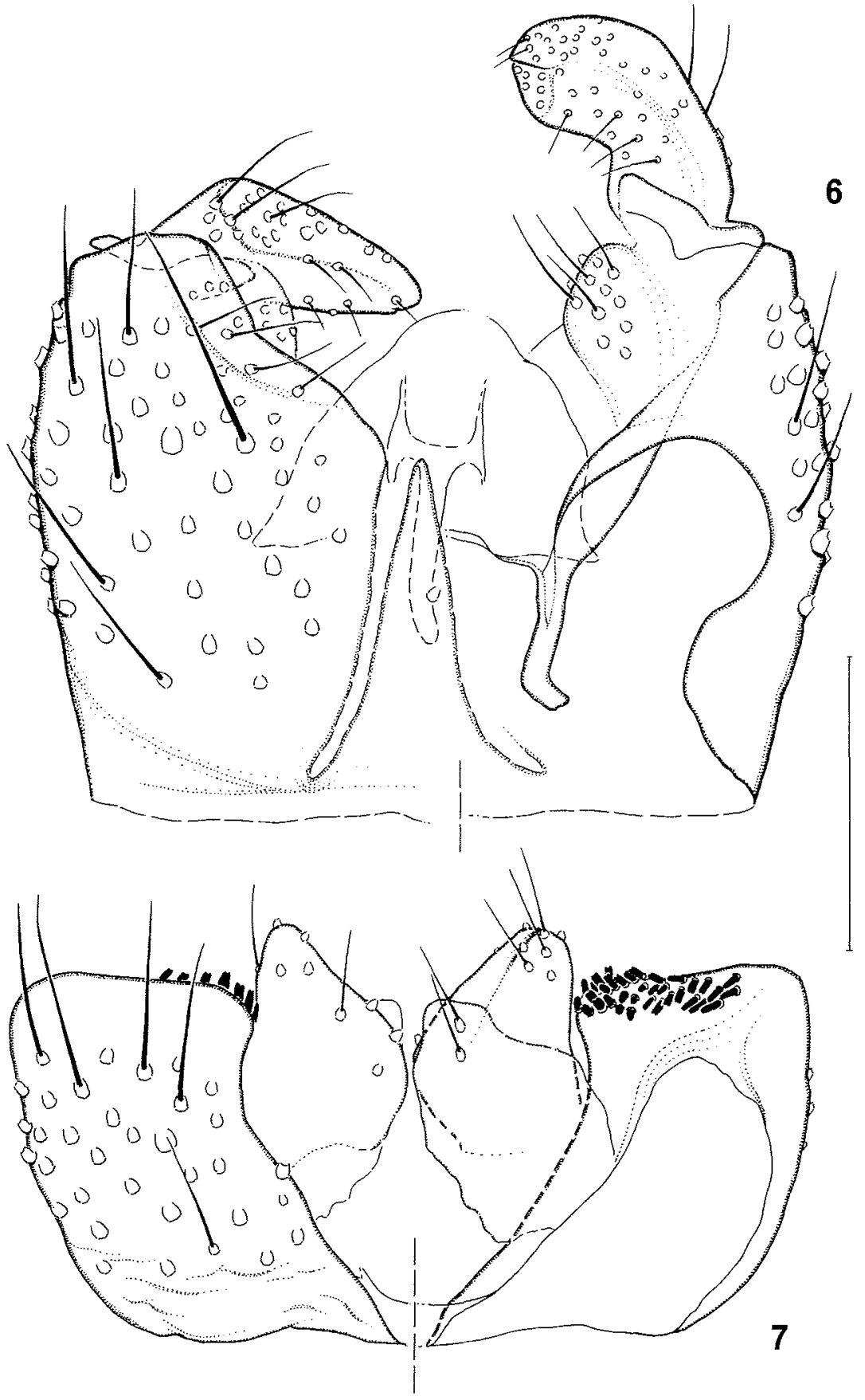

Figs 6, 7: Insulatricha bippai sp. n., male. - 6: terminalia; left side: ventral view, right side: dorsal view; - 7: tergite 9, cerci and hypoproct; left side: dorsal view, right side: ventral view. Specimen from Lake Daniells Track. (Length of scale bar: $0.1 \mathrm{~mm}$.). - 
rounded apically, densely setose. Hypoproct (Fig. 7) very weak, two-lobed, bearing 2 setae each distally.

Female. Unknown.

Types. Holotype: male, New Zealand, North Island, Taupo, Tongariro National Park, Mangawhero River valley $3 \mathrm{~km}$ NE Ohakune, $690 \mathrm{~m}$, in mixed podocarp/broadleaf forest, 26 Nov.-28 Dec. 2002, by Malaise trap, M. \& C. JASCHHOF \& U. KALLWEIT. Paratypes: 3 males, same data as holotype.

Discussion. As regards most characters, Insulatricha bippai is very much like I. chandleri (see next species), but clear differences between these two species lie in the male terminalia.

Distribution and phenology. Insulatricha bippai occurs on both main islands, but its distribution area appears to be confined to the central parts of the North Island (Ohakune, Mt Egmont) and the northern parts of the South Island (Buller area). Adults were collected by Malaise trapping and sweepnetting in prime, mature native forests of both the podocarp/ broadleaf and southern beech type. Middle elevations $(400-950 \mathrm{~m})$ are possibly preferred. Apparently the flight period is short and restricted to the early summer (November to mid-December). Numerous males but no females were collected. Insulatricha bippai was found to occur in the same sites like I. chandleriand Anisotricha novaezealandiae.

Etymology. 'This species is devoted to Prof. Dr HEIKKI HIPPA, Swedish Museum of Natural History, Stockholm, whose sustained interest in and original ideas on the phylogeny of the Sciaroidea has stimulated much of the work in this field over many years.

Other material studied. New Zealand / North Island / Taupo: 10 males, same data as types (in ethanol); Taranaki: 2 males (on slide), Mt Egmont, North Egmont, Holly Hut, 2630 Nov. 1975, from NZAC. South Island / Buller: 3 males (on slide), Nelson Lakes National Park, St Arnaud, 14-21 Nov. 1990, Landcare Nelson; 1 male (on slide), Nelson Lakes National Park, Lake Rotoiti, 20 Dec. 2000, DoC St Arnaud; 4 males (on slide), Lake Daniells Track $7 \mathrm{~km}$ E Springs Junction, 9 and 24 Nov. 2001, M. JASCHHOF; 1 male (on slide), $5 \mathrm{~km} \mathrm{~W}$ Maruia Springs, 26 Nov.-25 Dec. 2001, M. \& C. JASCHHOF.

\section{Insulatricha chandleri sp. $\mathrm{n}$.}

(Figs 8-17)

\section{Description}

Male. Body size: $3.2-4.3 \mathrm{~mm}$.

Head: Antennal flagellum with longest setae 1.5 times as long as the diameter of the flagellomere; with $4^{\text {th }}$ flagellomere (Fig. 8) 6.5 times as long as wide. Labrum non-setose. Maxillae with lacinia reduced in length, i.e. as long as palpomeres 1 and 2 together. Maxillary palpus segments 3 and 4 with sensory hairs. 
Legs: Fore tibia with anteroapical depression (Fig. 9) bearing straight comb of 14-19 spine-like setae subequal in length, with very indistinct rounded upper rim in some distance from the comb and short, fine setae between comb and rim. Wing: Venation: tb shorter or longer than mcu, and A1 usually shorter but sometimes longer than CuP.

Abdomen: Segment 8 shorter than half the length of segment 7 .

Terminalia: Gonocoxites (Fig. 12) ventrally broadly joined under incorporation of sternite 9 (which sometimes stands out from the gonocoxites as triangular portion mediobasally, see Fig. 13), with V-shaped ematgination ventrodistally; with setae of various lengths on its ventral and dorsal surfaces, setation absent from a portion ventroproximally, and very dense around the emargnation; with setose, elongate lobes in section 3 and bare, rounded lobes dorsoproximolaterally; dorsal gonocoxal apodemes unusually wide, with short, pointed processes directed inwards. Gonostyli (Figs 14,15) large, consisting of two large lobes subequal in size; with distal lobe setose outside and bare inside; with proximal lobe directed inwards, its apex incised, bearing minute tooth and setose swelling ventro-subapically, with many very short setae outside and inside; dorso-subbasally with another small, rounded, setose lobe; basolateral apophysis rather small. Aedeagus (Fig. 16) with long sclerotized apodeme widened apically into weakly sclerotized head, the latter with complicated structure that apparently is closely joined with the tegmen. Tegmen (Fig. 16) broad, with clear contours, distally with rounded lobe; ventral parameral apodemes short and sclerotized; dorsal parameral apodemes short, well sclerotized and connected by sclerotized transverse bridge. Tergite 9 (Fig. 17) toughly U-shaped, with long setae on its outer surface and many short, thorn-like, two-pointed megasetae inside distally. Cerci (Fig. 17) narrowly rounded apically, densely setose. Hypoproct (Fig. 17) very weak, twolobed, bearing 1 seta each distally.

Female. Body size: $3.1-3.3 \mathrm{~mm}$.

Head: Antenna with $4^{\text {th }}$ flagellomere (Fig. 10) 4 times as long as wide.

Legs: Fore tibia with anteroapical depression bearing comb of 9-11 spine-like setae, and with the fine setae between comb and rim fewer in number than in male, or completely absent.

Terminalia (Fig. 11): Distal cercus longer than wide. With 2 large, ovoid, well sclerotized spermathecae bearing many pores on their surfaces.

Types. Holotype: male, New Zealand, South Island, Buller, Maruia Forest, Shenandoah Saddle, $500 \mathrm{~m}$, in southern beech forest, 9 Oct.-3 Nov. 2001, by Malaise trap, M. \& C. JASCHHOF. Paratypes: 11 males, same data as holotype.

Discussion. Male terminalia in Insulatricha chandleri differ markedly from that in the congeneric species, I. hippai and catrinae (see next species). Striking differences lie in the structure of the gonocoxites (see Fig. 12 vs Fig. 6); gonostyli (see Figs 14, 15 vs Fig. 6); tegmen (see Fig. 16 vs Fig. 3 and Fig. 18, respectively); and tergite 9 (see Fig. 17 vs Fig. 7 and Fig. 19, respectively).

Distribution and phenology. Insulatricha chandleri is distributed on both main islands, with its distribution area apparently confined to the central North Island (Pureora Forest) and the northern and western South Island (Buller area and Westland coast). 

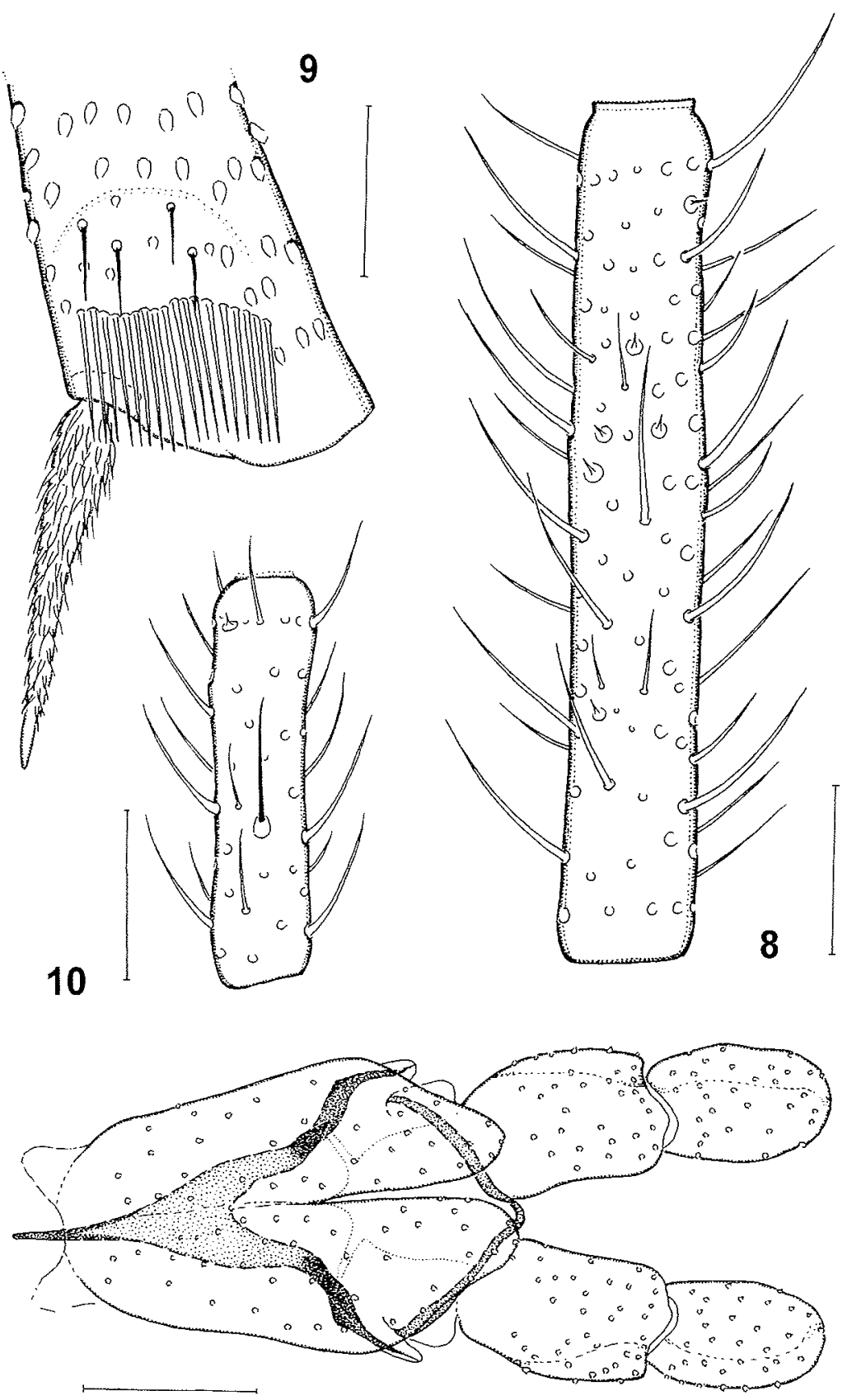

11

Figs 8-11: Insulatricha chandleri sp. n. - 8: male antennal flagellomere 4, dorsal view (0.05 mm); - 9: fore tibial anteroapical depression in male $(0.05 \mathrm{~mm})$; - 10: female antennal flagellomere 4 , dorsal view $(0.05 \mathrm{~mm})$; 11: female terminalia, ventral view $(0.1 \mathrm{~mm}) .8$, 9: paratypes; 10, 11: specimen from Pureora Forest. (In parentheses: length of scale bar.) 


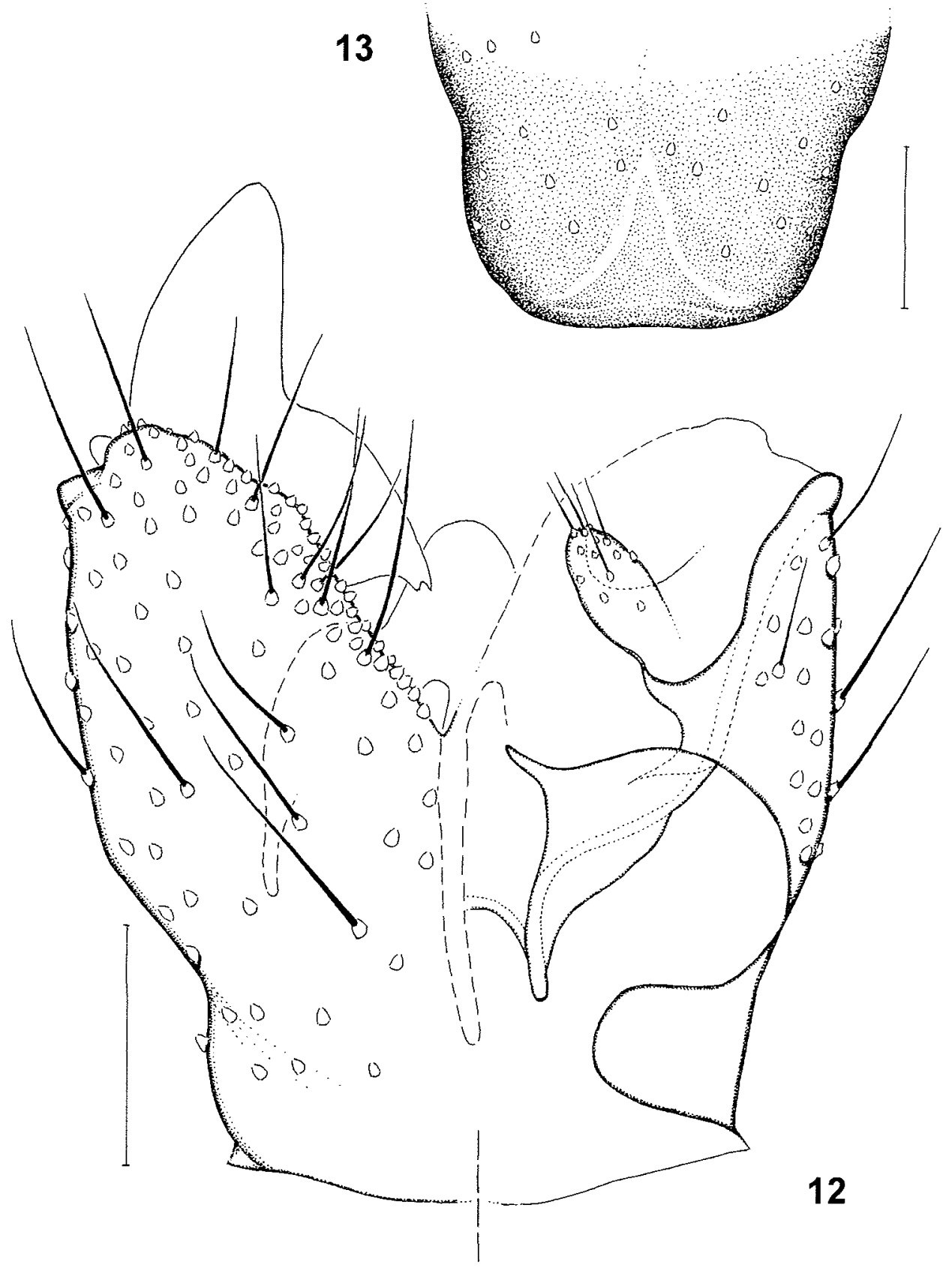

Figs 12, 13: Insulatricha chandleri sp. n., male. - 12: terminalia; left side: ventral view, right side: dorsal view $(0.1 \mathrm{~mm})$; - 13: proximal portion of gonocoxites with sternite 9 incorporated, ventral view $(0.1 \mathrm{~mm}) .12$ : holotype; 13: specimen from Pureora Forest. (In parentheses: length of scale bar.) 


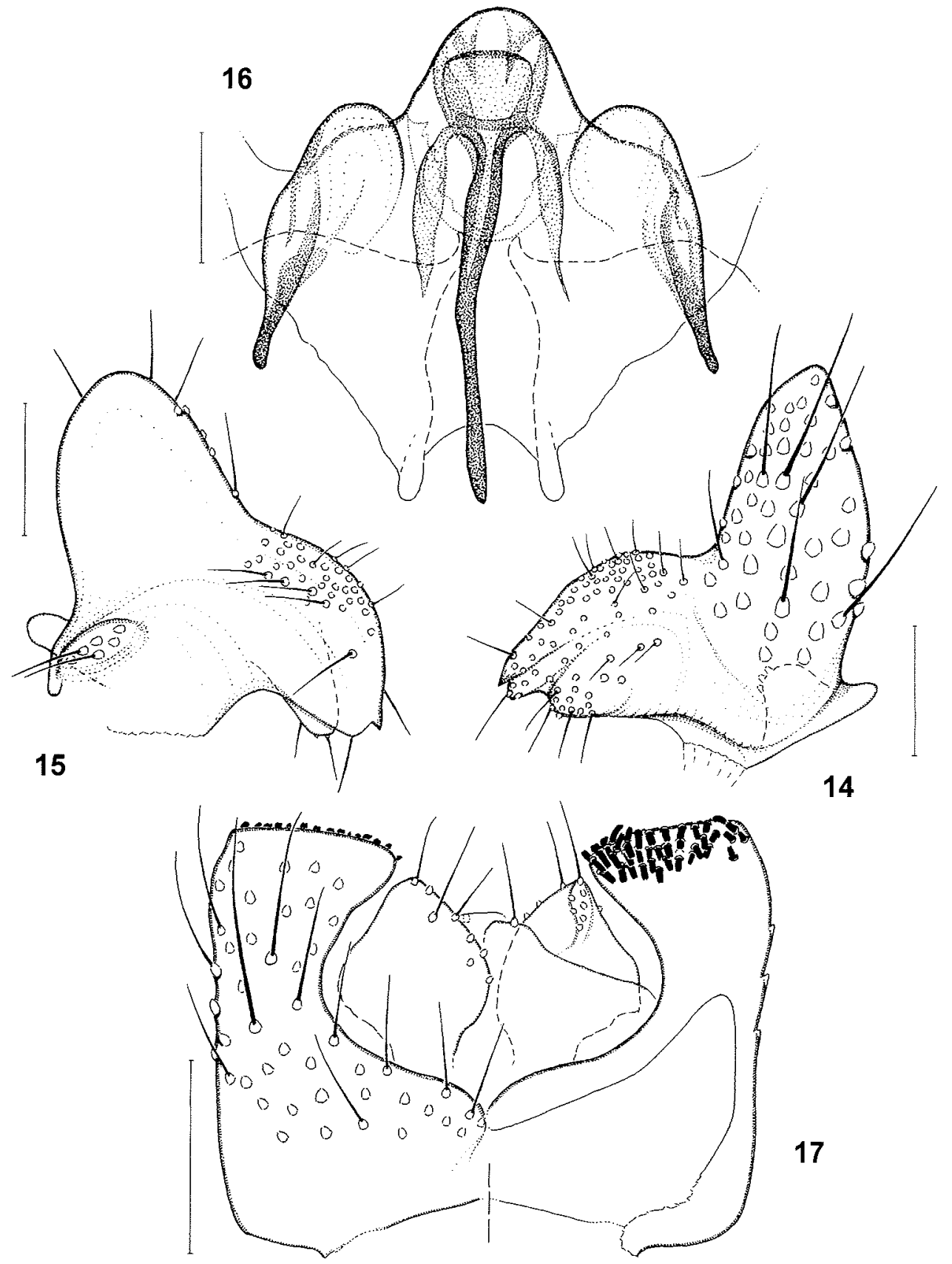

Figs 14-17: Insulatricha chandleri sp. n., male terminalia. - 14: gonostylus, ventral view $(0.05 \mathrm{~mm})$; - 15: ditto, dorsal (inside) view $(0.05 \mathrm{~mm}) ;-16$ : aedeagus and tegmen, ventral view $(0.05 \mathrm{~mm}) ;-17$ : tergite 9 , cerci and hypoproct; left side: dorsal view, right side: ventral view $(0.1 \mathrm{~mm})$. 14, 16: paratypes; 15 : specimen from Pureora Forest; 17: holotype. (In parentheses: length of scale bar.) 
Adults were collected exclusively by Malaise trapping in native podocarp/broadleaf and southern beech forests as well as in shrubland nearby native forest. Collection sites are located between 150 and $600 \mathrm{~m}$ altitude. The flight period is from September to December. Males were collected much more commonly than females. Insulatricha chandleri was found to occur at the same sites as bippai and catrinae (see next species).

Etymology. This species is named to honour PETER CHANDLER, Melksham, U.K., for his influential contributions to sciaroid research and, in particular, to the investigation of the Heterotricha group.

Other material studied. New Zealand / North Island / Taupo: 33 males, 11 females (on slide and in ethanol), Pureora Forest, Waipapa Reserve, 6 Oct.-3 Nov. 1983, J. HuTCHESON. South Island / Buller: 7 males (in ethanol), same data as types; 3 males (in ethanol), same locality as types but 3-25 Nov. 2001; 2 males (in ethanol), Lake Daniells Track $7 \mathrm{~km} \mathrm{E}$ Springs Junction, 24 Nov.-26 Dec. 2001, M. \& C. JASCHHOF; Westland: 3 males (in ethanol), Westland National Park, Canavans Knob, 12 Sept.-14 Oct. 1982, A.B. MLLER; 2 males, 3 females (all in ethanol), same locality but Oct.-Nov. 1982.

\section{Insulatricha catrinae sp. n.}

(Figs 18, 19)

\section{Description}

Male. Body size: ca. $2.8 \mathrm{~mm}$.

Head: Antennal flagellum with longest setae as long as the diameter of the flagellomere; with $4^{\text {th }}$ flagellomere 4 times as long as wide. Labrum setose. Maxillae with long, slender lacinia fringed terminally. Maxillary palpus segment 3 with sensory hairs.

Legs: Fore tibia with anteroapical depression bearing straight comb of 13-16 spine-like setae subequal in length, with very indistinct rounded upper rim in some distance from the comb and short, fine setae between comb and rim. Wing: Venation: tb longer than mcu, and $\mathrm{A} 1$ as long as or longer than $\mathrm{CuP}$.

Terminalia: Gonocoxites ventroproximally broadly joined and centrally with sternite 9 in between (distorted in slide preparations available for study); with setae of various lengths on its ventral and dorsal surfaces; with setose tounded lobes in section 3. Gonostyli turned inwards, broad proximally and wedge-shaped in distal half, with apex apparently simple; with long setae on outer surfaces and very short, fine setae inside and terminally; basolateral apophysis rather small. Aedeagus (Fig. 18) with long sclerotized apodeme; no further details visible, but its structure apparently rather simple. Tegmen (Fig. 18) long, with clear contours, distally with narrow head; dorsal parameral apodemes moderately long, well sclerotized and connected by weak transverse bridge. Tergite 9 (Fig. 19) plate-like, with long setae on its outer surface and narrow processes disto-laterally bearing short, thornlike, two-pointed megasetae. Cerci pointed apically, densely setose. Hypoproct very weak, two-lobed, apparently bearing 1 seta each distally.

Female. Body size: $2.7 \mathrm{~mm}$.

Head: Antenna with $4^{\text {th }}$ flagellomere almost 4 times as long as wide. 


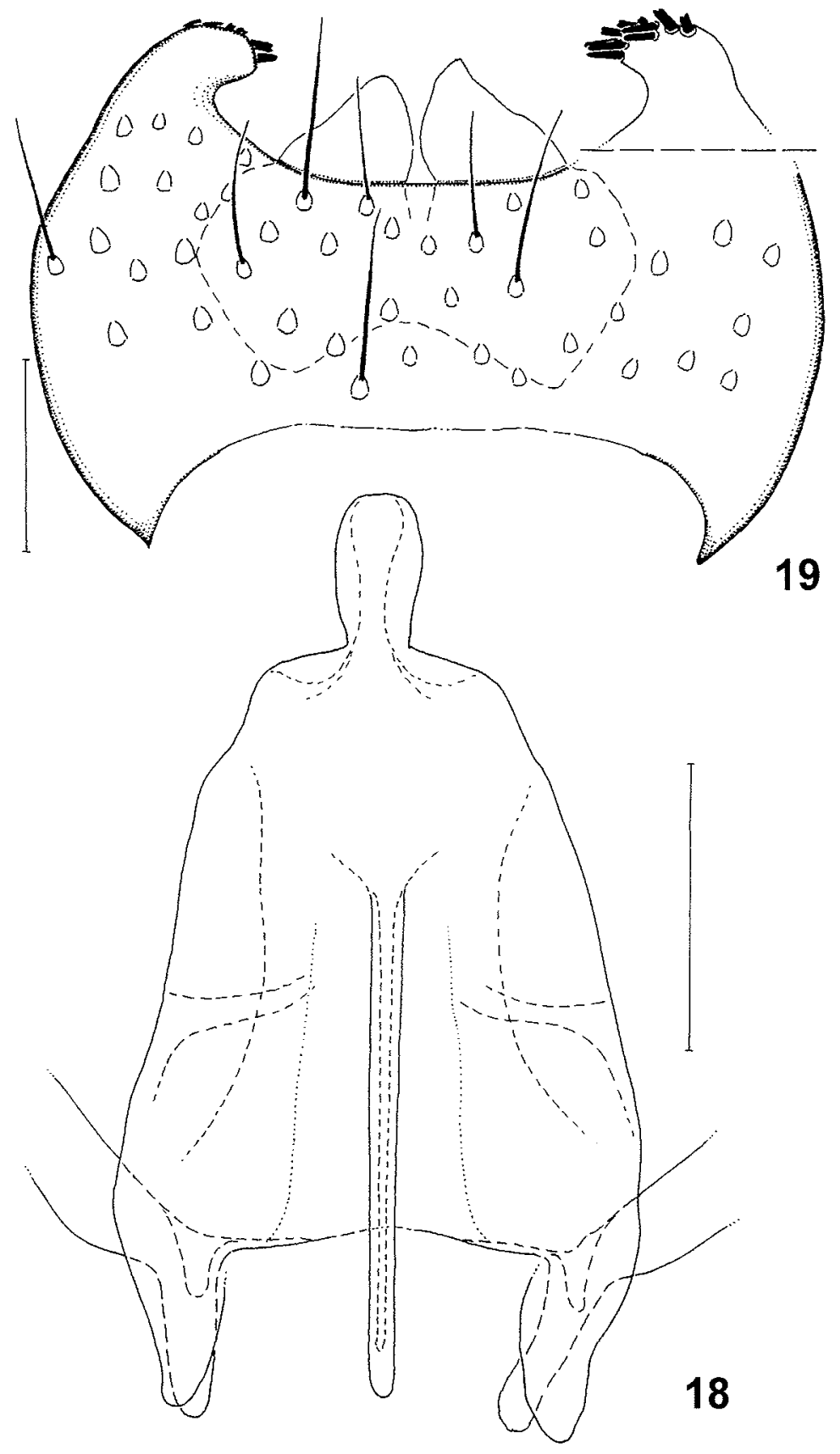

Figs 18, 19: Insulatricha catrinae sp. n., holotype male. - 18: aedeagus and tegmen, ventral view; - 19: tergite 9 with cerci indicated, dorsal view; right above: distolateral lobe, ventral view. (Length of scale bars: $0.05 \mathrm{~mm}$.) 
Terminalia: Distal cercus almost as long as wide. With 2 small, ovoid, well sclerotized spermathecae bearing pores on their surfaces.

Types. Holotype: male, New Zealand, North Island, Taupo, Pureora Forest, Waipapa Reserve, $570 \mathrm{~m}$, in podocarp forest, 20 Oct. 1983, by Malaise trap, J. HuTCHESON. Paratypes: 1 male, same locality as holotype but Oct. 1983; 1 female, same locality but 6 Oct. 1983.

Discussion. There are only two male individuals of this species available for study which due to the long storage in ethanol could not be cleared sufficiently; that is why several details of the terminalia cannot be described in as much detail as would be desirable. Insulatricha catrinae differs from its two congeners (in parentheses) in two points: the labrum is setose (non-setose) and the lacinia are well developed (largely reduced). Further differences are in the structure of the male terminalia (see under I. chandlen).

Distribution and phenology. Insulatricha catrinae is known from a single locality in the central North Island (Pureora Forest), where chandleri was found as well. For details of the collection site, see under'Types.

Etymology. I name this species after my wife, CATRIN JASCHHOF, Greifswald, in appreciation of her invaluable assistance in my various research projects on sciaroid flies.

\section{Genus Anisotricha CHANDLER, 2002}

This genus was recently proposed by CHANDLER (2002) for a single species, Heterotricha novaezealandiae TONNOIR in TONNOIR \& EDWARDS, 1927. Due to the fact that previous authors had only very few specimens of this species available for study, many details of the male terminalia remained unknown. Females were totally missing. Based on the availability of much more material of both sexes, I am now in a position to complete the species and genus descriptions. Moreover, microscopic study of the male terminalia of Anisotricha led to the recognition of another species very similar to novaezealandiae. This new species, Anisotricha similis, is described below.

\section{Supplement to the description}

Head: Postfrons slightly two-lobed, non-setose, with slightly two-pointed frontal tubercle. Face large, non-setose. Clypeus smaller than and clearly separated from face, setose. Scape somewhat conical, a little larger than pedicel, with ventral setae. Pedicel subglobular, with a few setae along distal margin. In males, flagellum without microtrichia except a few on flagellomere 1 basally. Each flagellomere with an even cover of setae arising from membranous rings, these setae as long as diameter of flagellomere or shorter; further with a few sensory spines. Flagellomeres 1(-3) dorsally with a few setae arising from sockets. In females, cover with microtrichia on flagellomere 1 more extensive, and setae arising from sockets more numerous and sometimes present also on flagellomere 4. Eyes with interommatidal setulae normally developed or much reduced. Labrum beak-like, well 
sclerotized, non-setose, fringed apically. Lingua with dense fringes apically. Maxillae with stipites separate and cardo absent; lacinia well developed, fringed apically. Maxillary palpus with 5 palpomeres, with the first palpomere ("presegment) well developed and setose. Palpomere 2 with a few wart-like sensillae distally; palpomere 3 not thickened, with short, hyaline sensory hairs accumulated in basal half; palpomere 5 extremely long, often longer than preceding two palpomeres together. Labium with prementum present as pair of setose lobes (often with only 1 seta each); premental apodeme sclerotized and with paired processes. Labial palpus 2 -segmented, labellum 1 smaller than 2; labellum 1 non-setose; labellum 2 with numerous, partly spine-like setae.

Thorax: Postpronotum present as collar-like structure above neck. Antepronotum subtriangular, with a few setae. Episternum 1 with a few setae. Epimeron 1 small, subtriangular. Scutum in profile evenly arched, with anterior parapsidal suture deep and median transverse suture barely traceable, almost entirely covered with setae. Scutellum with short setae and pairs of long setae. Prescutoscutal suture deep. Prescutum distinct, strongly sclerotized. Mediotergite high, in profile arched. Postphragma well developed, i.e. extending into abdominal cavity. Mediotergite and laterotergites with distinct suture in between. Laterotergite large, not pronounced. Anepisternum subrectangular; separated from preepisternum 2 by distinct suture. Anepisternal cleft deep. Preepisternum 2 much larger than anepisternum, subtriangular ventrally. Anterior and posterior basalare distinct. Midpleural pit distinct. Epimeron 2 with deep cleft dorsally indicating a subdivision into upper anepimeron and lower katepimeron, the latter strongly narrowed ventrally. Metanotum very short, barely traceable. Episternum 3 subdivided by a cleft into a small, indistinct upper portion (situated behind posterior spiracle) and large, subrectangular lower portion, the latter setose. Epimeron 3 very narrow. Openings of spiracles without striking features. Legs: Coxae longer than half the height of thorax. Coxae and femora with setae of moderate length. Tibial spurs 1:2:2, well developed. Fore tibial anteroapical depression well developed, with distinct, U-shaped proximal rim; depression bearing many setae, including those forming a comb distally. Tibiae and tarsi covered with large trichia and short setae; mid and hind tibiae and tarsi of all legs with a few short, strong projecting setae. Tarsomeres 1-5 gradually decreasing in length. Pretarsal claws small, somewhat curved, without teeth. Pulvilli well developed, as long as empodia. Empodia half as long as claws. Wing: Long, i.e. more than two times as long as wide, but shorter than body. Calyptral area somewhat convex; anal area moderately developed. Membrane covered with setae with setation less dense towards wing base and anterior margin, i.e. costal cell lacking setae and basal cell with strongly reduced setation. Venation: C extending to apex of wing, ending at a point half way between apices of R 5 and $M 1$; Sc long, ending abruptly beyond level of Rs; Rs oblique, slightly curved, much longer than ta; ta oblique; R5 with short faint portion proximally; $M$ absent; $M 1+2$ stem shorter than fork, the latter clearly diverging; tb + mcu almost parallel to anterior wing margin, tb longer than mcu; $\mathrm{CuP}$ reaching to or going beyond half length of $\mathrm{CuA2}$; 11 shorter than CuP; $\mathrm{A} 2$ barely traceable. With setae present along wing margin and on $\mathrm{Sc}, \mathrm{R}, \mathrm{R} 1$ (dorsally and ventrally), sometimes Rs, R5 (dorsally and ventrally), $M 1+2$ stem and fork (dorsally and ventrally), ta, tb (dorsally and ventrally), sometimes mcu, CuA1 (dorsally and ventrally), CuA2, and A1. Pattern of sensory pores: R, 0-1; R1, 3-4; Rs, 1-2; R5, 1-2 proximally, 1-3 distally.

Abdomen: Tergites evenly covered with long setae. Tergite 1 and sternite 1 each subdivided into long anterior and short posterior plates with a membranous portion in between. Tergite 1 shorter than 2 , and 7 longer than 8 . Sternite 1 setose. Sternite 2 with 
two membranous windows anteriorly separated by sclerotized bar bearing numerous sensory setulae. Membranous portions on sclerites 1 and 2 obviously creating a flexible zone enabling the abdomen to be bent behind segment 1. Sternites $2-8$ with long setae arranged in three irregular longitudinal rows. With six pairs of spiracles, one each on segments 2-7. Tergal plaques small, situated in a anterolateral position on each tergite, with their pattern $0 / 1 / 1 / 1 / 1 / 1 / 1 / 0$.

Terminalia. Male. Sternite 9 present as distinct sclerite. Gonocoxites fused ventrobasally and -distally and having sternite 9 incorporated in between, with setose lobe in gonocoxal section 3; gonocoxal apodemes not forming a transverse bridge but interlinked through the dorsal wall of tegmen. Gonostyli with sweeping lobes. Aedeagus consisting of a basiphallus with long sclerotized apodeme, and a sclerotized, two-part 'distiphallus'. Parameres intimately fused to form a tegmen, with sclerotized 'teeth' distolaterally; with large, smooth lobe each dorso-proximolaterally bearing many long, strong trichia, and arising from this lobe, with long, smooth, ribbon-like appendage bearing long trichia most striking terminally; tegmen dorsomedially linked with lateral appendages of gonocoxal apodemes; dorsal 'parameral apodemes' (actually, clearly prolongations of the gonocoxal apodemes!) very long and strongly sclerotized. Tergite 9 plate-like, subtrapezoid, with slight, setose swelling distomedially. Tergite 10 absent or (if correctly identified) present as smooth, setose lobe. Cerci large, subtriangular, with fine, long setae distally. Hypoproct weak, paired or simple, non-setose or setose. Female. Slightly deviating from basic pattern in Sciaroidea (see under A. novaezealondiae). With 2 sclerotized spermathecae.

Discussion. CHANDLER's (2002) definition of the genus Anisotricha was necessarily based on $A$. novaezealandiae and, after study of the second species, $A$. similis (see below), can herewith be confirmed. After the addition of characters of the female, the definition reads as follows: the antennae are upturned and with the flagellum long (plesiomorphous conditions); the clypeus is unproduced (plesiomorphous); episternum 3 is setose (apomorphous); the wing veins, including Sc, bear setae (plesiomorphous), while the setation on the membrane is somewhat reduced (apomorphous); Rs is oblique and longer than ta, with the latter also oblique (plesiomorphous); the stem of $\mathrm{M} 1+2$ is rather short, i.e. shorter than the fork (plesiomorphous); the parameres are fused to form a tegmen (apomorphous); the male tergite 9 is mainly unmodified (plesiomorphous); the ovipositor is shortened (apomorphous); and two sclerotized spermathecae are present (plesiomorphous). As usual with genera of the Heterotricha group, this definition is polythetic, and autapomorphous characters are not recognizable of Anisotricha, except possibly those of the terminalia (see below). Episternum 3 is setose also in Rhynchobeterotricha, Afrotricha and Chiletricha; the setation on the wing membrane is reduced also in Rhynchobeterotricha and Chiletricha; and a tegmen is developed in Insulatricha, Cbiletricha, Sciaropota and possibly others. In Anisotricha, male terminalia are very peculiar by the presence of a well developed 'distiphallus' and trichose appendages of the tegmen. The latter might indicate a secondary subdivision of the parameres into ventral and dorsal portions - with the appendages representing the dorsal portion - a condition that is apparently absent in other members of the Ieterotricha group and, if explained by secondary acquisition, an autapomorphous character of Anisotricha. The homology of the 'distiphallus' in Anisotricha is difficult to assess, but a corresponding structure scems to be present in Chiletricba penae CHANDLER, 2002 (CHANDLER, 2002: 122, Fig. 39). The 
ovipositor in Anisotricha gaines its shortness mainly through the very short distal cerci, which is unique within the Tleterotricha group as so far known, but otherwise difficult to compare as the females in several genera are not yet known.

\section{Anisotricha novaezealandiae (TONNOIR in TONNOIR \& EDWARDs, 1927)}

(Figs 20-26)

\section{Supplement to the description}

\section{Male. Body size: $3.8-4.3 \mathrm{~mm}$.}

Head: Antenna with $4^{\text {th }}$ flagellomere almost 7 times as long as wide. Eyes with reduced number of interommatidal setulae. Maxillary palpus with palpomere 1 bearing 1-2 setae.

Legs: Fore tibia with anteroapical depression bearing a distal comb of up to 20 setae (Fig. 20). Terminalia: Gonocoxites (Fig. 21) strongly setose ventrally and dorsally, except more membranous portions ventrocentrally and -proximally; ventro-mediodistally with weak lobe bearing many fine trichia; with narrow, setose lobe in section 3. Sternite 9 (Fig. 21) triangular, non-setose. Gonostyli (Fig. 22) with narrow, non-setose basal portion ('stem') and sweeping, roughly crescent-shaped distal portion, the latter bearing a group of short setae on its outermost portion and fine setulae elsewhere; basolateral apophysis well developed. Basiphallus of aedeagus (Fig. 23) with long, sclerotized apodeme and membranous apical portion bearing an appendage each lateroproximally; distiphallus (Fig. 23) consisting of two parts each forming roughly an inverted V-structure. Tegmen (Fig. 23) large, mainly membranous, with sclerotized ventral parameral apodemes, with 2 sclerotized 'teeth' each distolaterally; with ribbon-like appendage very long, variously curved and bearing dense brush of trichia terminally (Fig. 21). Tergite 9 (Figs 24,25) rather long, densely setose, with slight swelling mediodistally bearing many spine-like setae directed inwards. Cerci as in Fig. 24. Tergite 10 absent. Hypoproct (Fig. 24) simple, non-setose, with dense cover of long microtrichia.

Female. Body size: $3.5-4.3 \mathrm{~mm}$.

Head: Antenna with $4^{\text {th }}$ flagellomere almost 5 times as long as wide.

Terminalia (Fig 26): With gonocoxites 8 extending caudally far beyond tergite 10 , gonocoxite and gonapophysis 8 widened caudally, densely setose; gonapophyses 9 present as broad, well sclerotized internal ribs that merge anteriorly to form a notum with long, narrow process; tergite 10 well developed; sternite 10 present as internal ribs merging posteriorly and bearing marginal setae; proximal cerci well developed; distal cerci very short and blunt-ending. Spermathecae large, flattened, circular, lacking pores on their surfaces.

Distribution and phenology. Anisotricha novaezealandiae appears to be confined to the northern South Island (Nelson and Buller areas). The specimens studied here come from the extensive southern beech forests, that are sometimes mixed with podocarp trees, of the Nelson Lakes National Park, from elevations between 450 and $700 \mathrm{~m}$. This area is in close distance to the species' type locality, Aniseed Valley near Nelson, where most of the origi- 

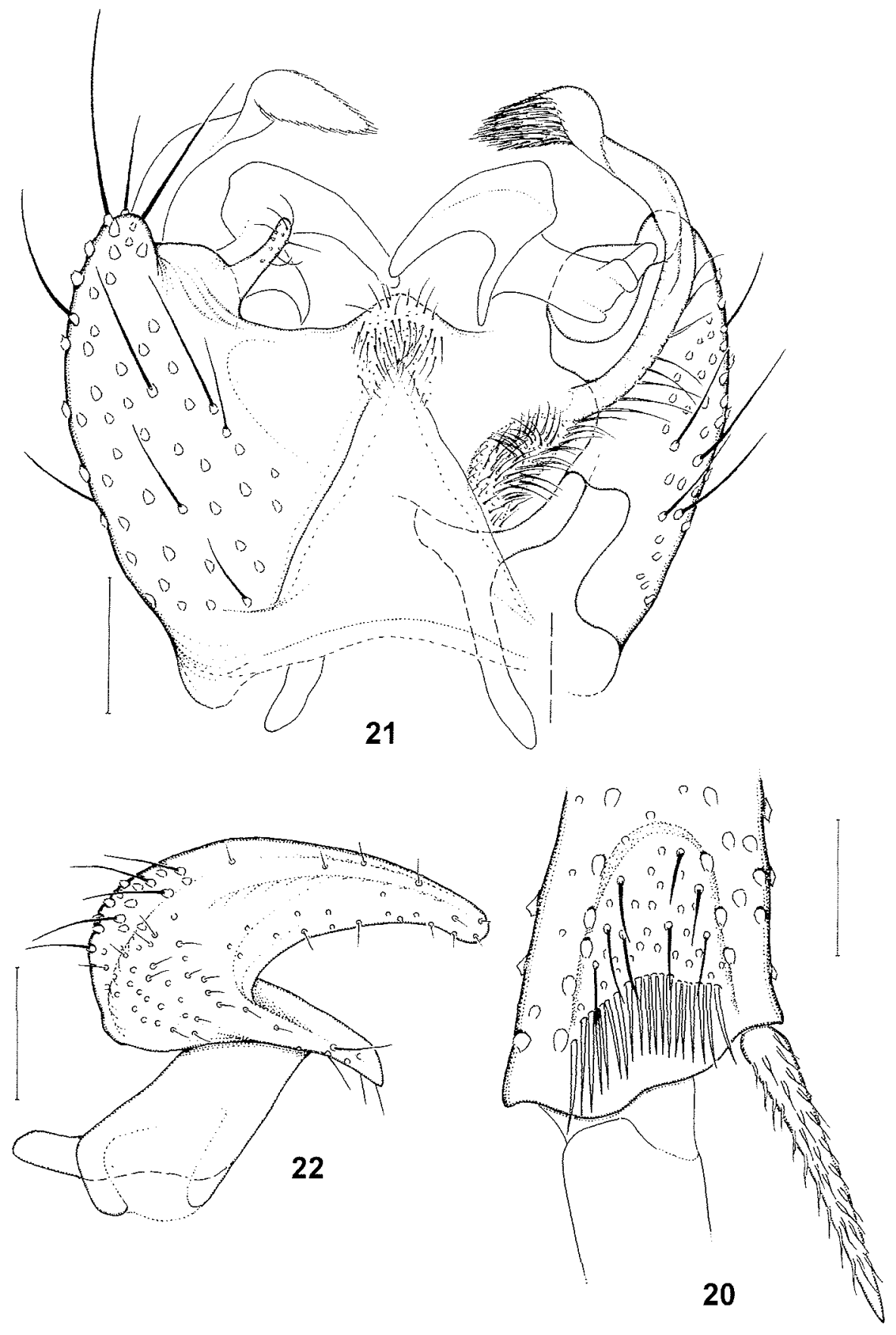

Figs 20-22: Anisotricha novaezealandiae (TONNOIR), male. - 20: fore tibial anteroapical depression $(0.05 \mathrm{~mm})$; - 21: terminalia; left side: ventral view, right side: dorsal view $(0.1 \mathrm{~mm})$; - 22: gonostylus, dorsal view $(0.05 \mathrm{~mm}) .20-22$ : specimens from Lake Rotoroa. (In parentheses: length of scale bar.) 


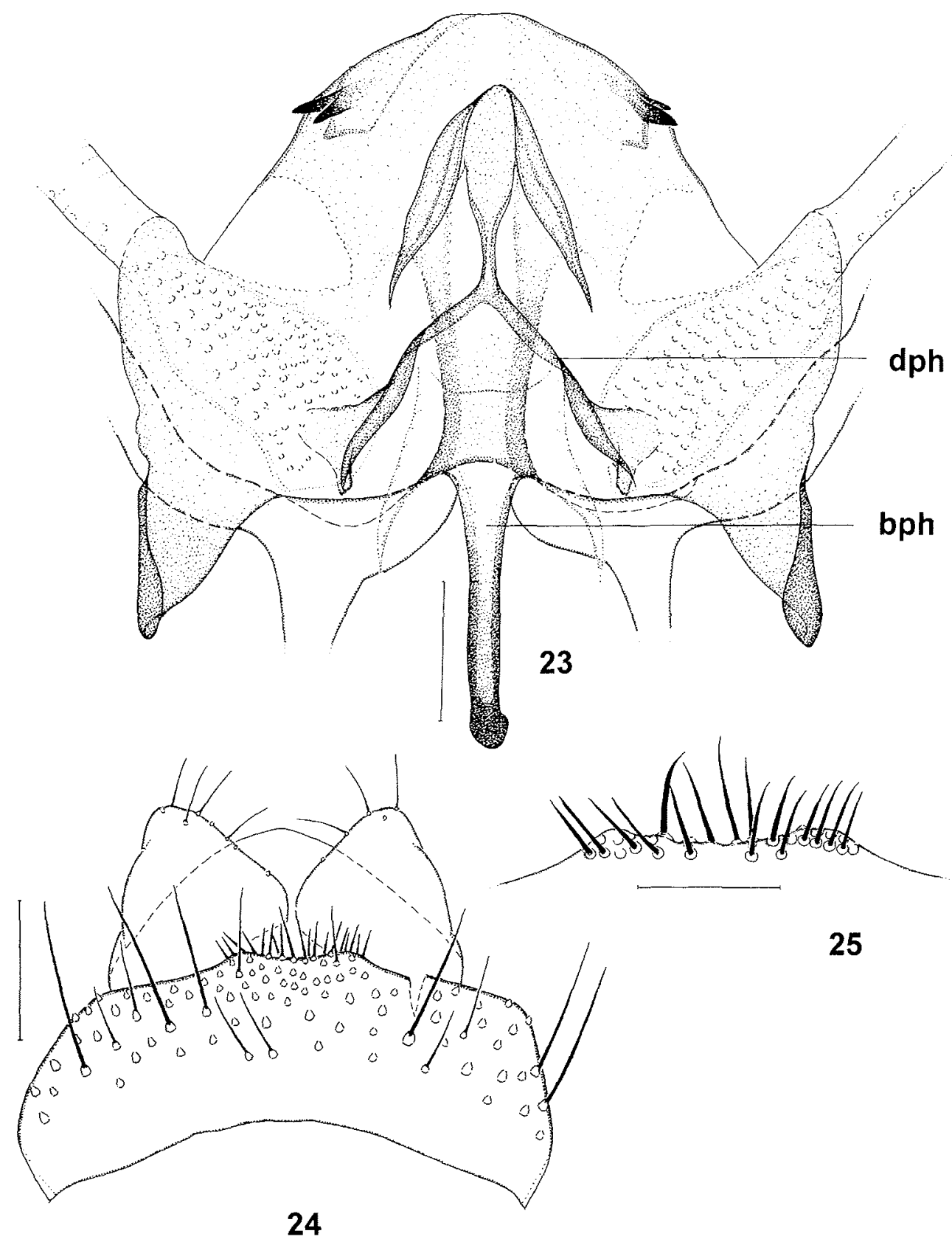

Figs 23-25: Anisotricha nonaezealandiae (TONNOIR), male. - 23: aedeagus and tegmen, ventral view $(0.05 \mathrm{~mm})$; - 24: tergite 9, cerci and hypoproct; dorsal view $(0.1 \mathrm{~mm})$; - 25: mediodistal tim of tergite 9, ventral view $(0.05 \mathrm{~mm})$. 23-25: specimens from Lake Rotoroa. (In parentheses: length of scale bar.) Abbreviations: bph $=$ basiphallus, $\mathrm{dph}=$ distiphallus. 


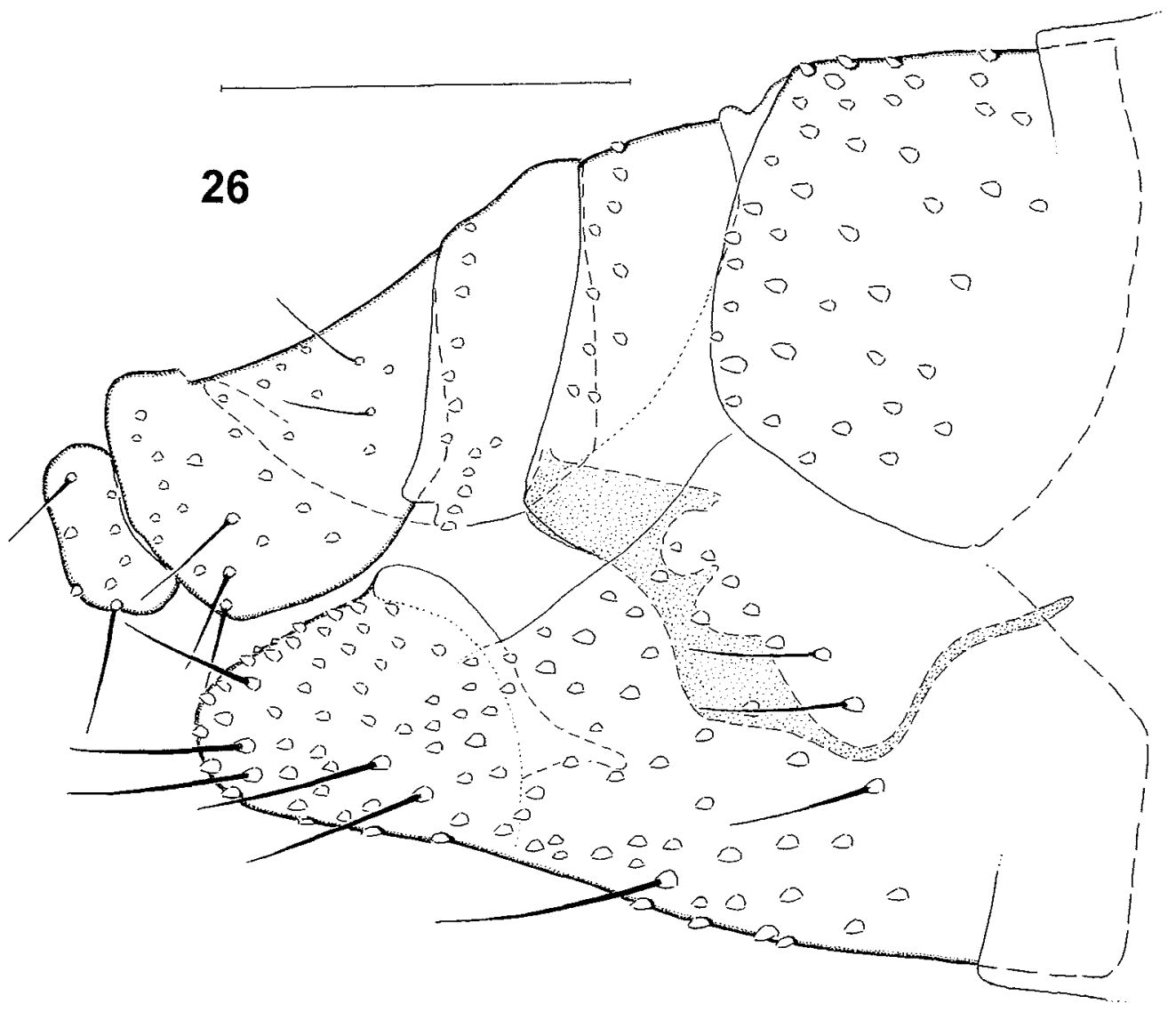

Fig. 26: Anisotricha novaezealandiae (TONNOIR), female. Terminalia, lateral view (gonapophyses 9 punctured). Specimen from Lake Rotoroa. Length of scale bar: $0.2 \mathrm{~mm}$.

nal forest had to make way for human settlements. The specimens studied were Malaise trapped in mid summer (December/January). Males were collected 20 times more commonly than females. Insulatricha hippai was shown to occur at the same sites as Anisotricha novaezealandiae.

Material studied. New Zealand / South Island / Buller: 26 males (in ethanol), 1 male, 1 female (both on slide), Nelson Lakes National Park, Lake Rotoiti, 27 Dec. 2000-30 Jan. 2001, Department of Conservation St Arnaud; 3 males (in ethanol), same locality but 29 Dec. 1998; 40 males (in ethanol), 8 males, 3 females (all on slide), Nelson Lakes National Park, Lake Rotoroa, 19-27 Dec. 2000, Department of Conservation St Arnaud; 6 males (in ethanol), Nelson Lakes National Park, St Arnaud, 11-18 Jan. 1991, Landcare Nelson. 


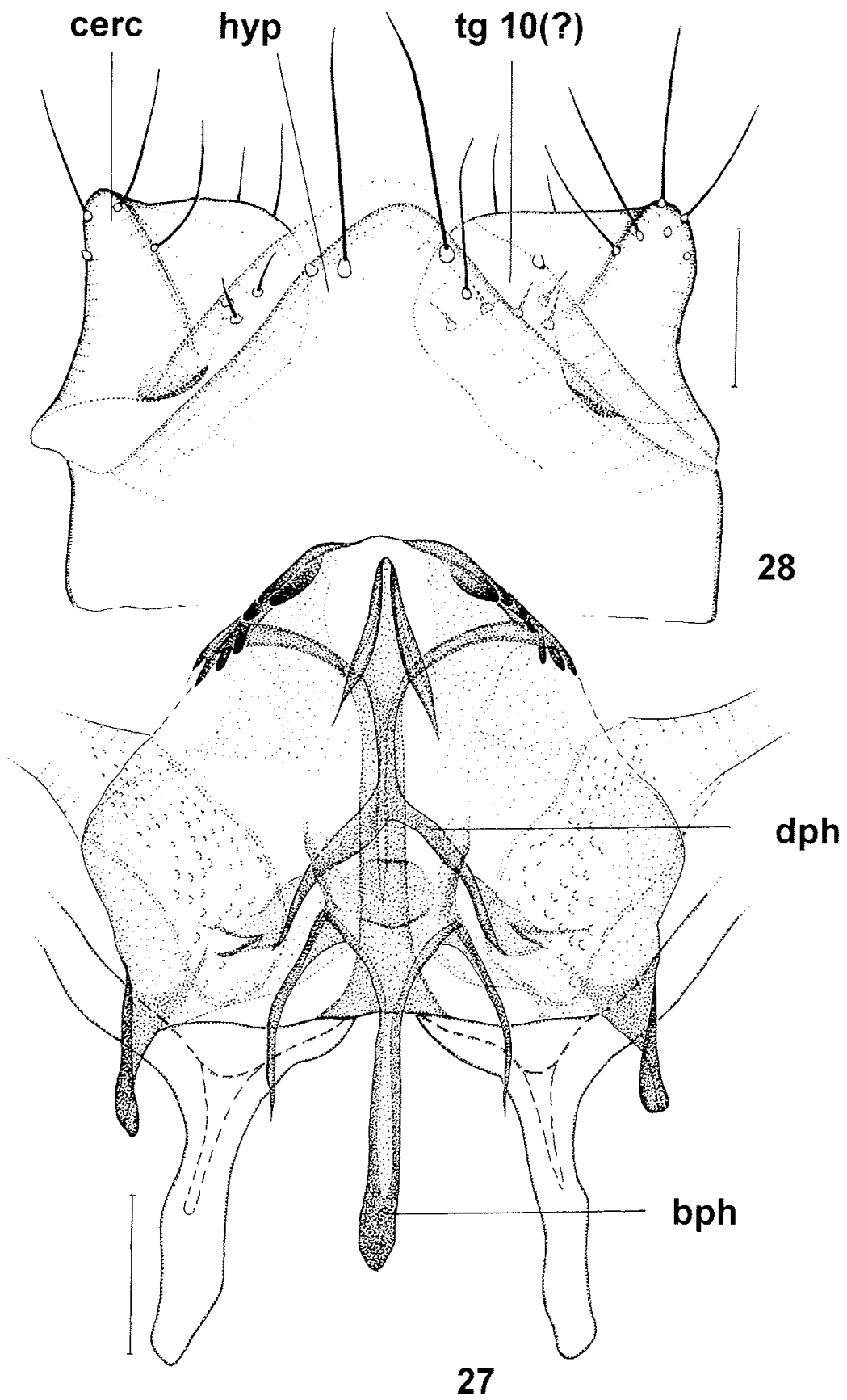

Figs 27, 28: Anisotricha similis sp. n., male. - 27: aedeagus and tegmen, ventral view; - 28: hypoproct, tergite 10 and cerci, ventral view. 27: holotype; 28: paratype. Length of scale bar: $0.05 \mathrm{~mm}$. Abbreviations as in Fig. 23 , and further: cerc $=$ cerci, $\operatorname{tg} 10=$ tergite 10, hyp $=$ hypoproct. 


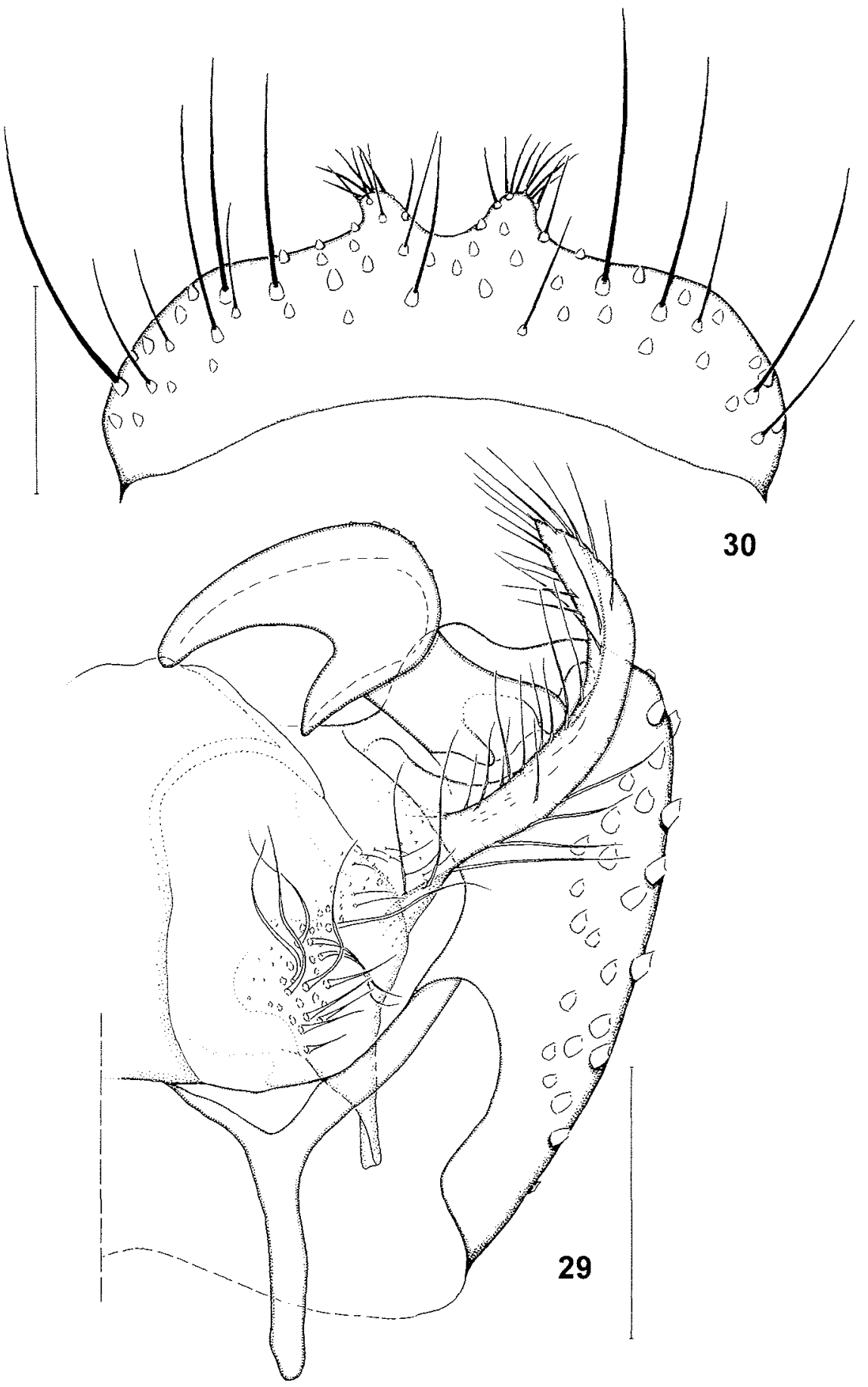

Figs 29, 30: Anisotricha similis sp. n, holotype male. - 29: terminalia (right half), dorsal view; - 30: tergite 9, dorsal view. Length of scale bars: $0.1 \mathrm{~mm}$. 


\section{Anisotricha similis sp. n.}

(Figs 27-30)

\section{Description}

Similar in most respects to the previous species with the differences as follows:

Male. Body size: $3.5-4.3 \mathrm{~mm}$.

Head: Antenna with $4^{\text {th }}$ flagellomere 6 times as long as wide. Eyes with normal density of interommatidal setulae. Maxillary palpus with palpomere 1 stronger and bearing 3-4 setae.

Terminalia: Compared with $A$. novaezealandiae, distal portion of basiphallus (Fig. 27) more extensively sclerotized; tegmen (Fig. 27) more extensively sclerotized distally and bearing up to 7 teeth each distolaterally; trichose (parameral) lobes narrower and ribbon-like appendages much shorter, not curved and less densely trichose terminally (Fig. 29); tergite 9 (Fig. 30) shorter and with 2 setose lobes mediodistally; tergite 10 (Fig. 28), if correctly identified, present as smooth lobe bearing a few short, spine-like setae; and hypoproct (Fig. 28) with 2-4 long setae distally.

Female. Unknown.

Types. Holotype: male, New Zealand, South Island, Fiordland, Fiordland National Park, $3 \mathrm{~km}$ E Milford Sound, in mixed podocarp/broadleaf forest, 21 Dec. 2002, by sweepnet, M. JASCHHOF. Paratypes: 5 males, South Island, Otago Lakes, Fiordland National Park, Eglinton River valley, Deer Flat, in southern beech (Nothofagus spp.) forest, 4-24 Jan. 2002, M. \& C. JASCHHOF.

Discussion. Anisotrich a similis is practically indistinguishable from novaezealandiae except by structural details of the male terminalia (see description above).

Distribution and phenology. Anisotricha similis appears to be confined to the southern South Island (Fiordland, Otago Lakes and Southland areas). The few known specimens were collected in southern beech and mixed podocarp/broadleaf forests in mid summer (December/January). Given the small morphological distance between them, one may assume that $A$. similis and novaezealandiae are rather young vicariant species, possibly having diverged in the result of Pleistocene glaciation.

Etymology. The specific name is Latin meaning 'similar', referring to the similarity with A. novaezealandiae.

Other material studied. New Zealand / South Island / Southland: 1 male, Catlins, Purakaunui Scenic Reserve, 3 Jan. 2002, M. JASCHHOF.

\section{Relationships of Anisotricha and Insulatricha within the Heterotricha group}

The delimitation of the Heterotricha group from other Sciaroidea is based on the corresponding wing venation of the species included; however, the so-defined group is not necessarily monophyletic (CHANDLER, 2002). When other characters are taken into 
consideration, a core-group consisting of Cbiletricha, Rbynchoheterotricha, Anisotricha, Heterotricha and Afrotricha is ascertained, while Nepaletricha and Kenyatricha, and even more so Sciaropota and Sciarosoma appear to be as distantly related to the core as do other Sciaroidea, like Sciaridae, Obakunea and Colonomyia (CHANDLER, 2002). The close relationship between Feterotricha, Afrotricha and Chiletricha was inferred from similarities in the female terminalia, while the structure of the male terminalia led both to the assumption that Rbynchobeterotricha and Anisotricha would belong to the same clade and to the anticipation of similar female structures (CHANDLER, 2002). Still nothing can be said on the female structures in Rbynhobeterotricha, but in the two New Zealand genera Anisotricha and Insulatricha the female terminalia differ from each other and from the genera referred to above - and thus do not support the assumption of closer relationship. The distribution of other characters in Insulatricha does also not support the argumentation advanced by CHANDLER (2002: 142, cladogram Fig. 103). In detail, in Insulatricha the episternum 3 is bare (character 17 in CHANDLER's cladogram), which contradicts its assignment to a clade (Chiletricha + Rhynchobeterotricha) + Anisotricha; male tergite 9 bears spinose processes (or, as here called, short megasetae distolaterally) (character 14), which indicates its belonging to a clade Cbiletricha+Rhynchobeterotricha; and vein $S_{c}$ is setose (character 15), which contradicts its assignment to such a clade. As so often in phylogenetic considerations on Sciaroidea, the addition of new taxa causes conflict and more confusion rather than leading to support and better resolution. As CHANDLER (2002) states, " ".. strongly apomorphous characters are either autapomorphous in particular subordinate taxa ... or have developed independently in more than one family ...", and this seems to apply to the Heterotricha group as well.

There is no doubt that both Insulatricha and Anisotricha are distinct, monophyletic groups. One should expect that these two New Zealand genera are more closely related to one another than to genera outside New Zealand, but the opposite seems to be true. On the basis of the male terminalia - in particular the structure of tergite 9 - Insulatricha appears to be most closely related to Chiletricha, even though several details of the genitalic structures in the latter genus are not yet described (for instance, the outline of sternite 9 and the fine structure of the 'spines', or megasetae, on tergite 9). In contrast, Anisotricha with its strongly derived male genitalic structures (see, in particular, gonostyli, phallus and parameres) holds a rather isolated position among the genera of the core group where it undoubtedly belongs to.

\section{Position of the Heterotricha group within the Sciaroidea}

CHANDLER (2002) discusses in length the development of ideas on the phylogenetic relationships between family-level taxa of the Sciaroidea and makes it clear that most of the argumentation advanced by previous authors is based - due to the scarcity of other useful characters - on larval morphology and wing venation. As regards the Heterotricha group, larvae have not yet been found, a fact which leaves almost all phylogenetic consideration to wing venation. However, wing venation in the Sciaroidea provides a character set that is notorious for the extent of homoplasy involved. The previously practised assignment of Heterotricha to the family Diadocididae resulted mainly from such formal interpretations of vein patterns. To put it in drastic terms, one and the same vein pattern may be explained in different ways depending on what interpretation best fits into a certain argumentation scheme. This is particularly true for pre-Tertiary fossils in which the more or less com- 
pletely preserved wing venation often is the more easily, or even only exploitable source of information. Such fossils may be helpful in reconstructing general tendencies, or main stages in the evolution of venation (see MATILE, 1981), but they may be object of speculation rather than interpretation in a particular taxonomic case. It is for such reasons that the author cannot accept the inclusion of Mangas exilis KOViLEV into the Heterotricha group (CHANDLER, 2002).

Admittedly, after the study of the New Zealand representatives of the Heterotricha group we are not provided with better arguments in order to decide whether or not the group is monophyletic and where to place it within the Sciaroidea. At present, it appears that the group represents one or two extant lineage(s) of ancient sciaroids that have their origin in the broadly developed Jurassic stock of fungus gnats in the broadest sense. This group obviously retained the type of venation that is not found in other extant Sciaroidea but predominated in an earlier, Jurassic radiation of the Sciaroidea. What we learned in New Zealand is that the search for Heterotricha-like flies - and certainly also their larvae - is more calculable than expected only a few years ago. These flies seem to be not so exceedingly rare if one only knows where and when to look for them. Currently we can do little more than to continue searching for new study material - adults and larvae - in order to get a more realistic idea of the variety and distribution of the characters and character states we work with.

\section{Key to the New Zealand species of the Heterotricha group (males)}

Remark: There might be species-specific characters even in females, as evidenced by the species-pair Insulatricha chandleri and catrinae, but the females of two of the five species in question are still unknown and thus not available for a comparative study.

1 Episternum 3 setose; stem of $\mathrm{M} 1+2$ clearly shorter than its fork; tergite 9 without numerous short megasetae each distolaterally .... (Genus Anisotricha CHANDLER) 2 Episternum 3 non-setose; stem and fork of M1 +2 subequal in length; tergite 9 with numerous short megasetae each distolaterally ............ (Genus Insulatricha gen. n.) 3

2 Tergite 9 with slight swelling mediodistally bearing many spine-like setae; parameral ribbon-like appendages very long, variously curved and bearing dense brush of trichia terminally A. novaezealandiae (TONNOIR)

- Tergite 9 with 2 setose lobes mediodistally bearing many spine-like setae but without such setae in between the lobes; parameral ribbon-like appendages shorter, not curved and less densely setose terminally A. similis sp. n.

3 Labrum setose; tergite 9 with small lobe each distolaterally bearing some 10 short megasetae ........................................................................... . catrinde sp. n.

Labrum non-setose; tergite 9 of another shape ................................................. 4

4 Tergite 9 almost completely subdivided medially; sternite 9 present as distinct sclerite; gonostyli simple I. bippaisp.n.

Tergite 9 with emargination mediodistally extending over two thirds of the tergite's length; sternite 10 fully incorporated in ventral gonocoxal bridge; gonostyli twolobed I. chandlenisp. a. 


\title{
Acknowledgements
}

This study was made possible through the granting of a The Linnean Society of London award. The collection of study material was supported by grants of the Deutsche Forschungsgemeinschaft, Bonn, Germany (JA 1020/1-1 and -2). I am grateful to PETER M. JOHNS, Canterbury Museum, Christchurch, New Zealand, for his authorisation to collect Diptera specimens under his permit (\#9900/142/3/04) and most valuable advice concerning collection localities throughout New Zealand. Study material was contributed by the New Zealand Arthropod Collection, Mt Albert, Auckland (Dr TREVOR K. CROSBY); Landcare Research, Nelson (RICHARD TOFT); and the Department of Conservation, St Arnaud (through mediation by R. TOFT). I gratefully acknowledge the support of the Canterbury University, Department of Zoology, Christchurch during my postdoc stay in 2001/02 (host: Dt RAPHAEL K. DIDHAN). I am most grateful to my wife, CATRIN JASCHHOF, for sorting through a considerable quantity of insect material in order to find the flies dealt with here. I thank PETER CHANDLER, Melksham, U.K., and Prof Dr HEIKKI HIPPA, Swedish Museum of Natural History, Stockholm, for the most useful correspondence on various aspects of sciaroid phylogeny. Language of the manuscript was kindly improved by Ms. BIRGIT SIEVERT, Berlin. Dr FrANK MENZEL, Deutsches Entomologisches Institut, Eberswalde, Germany, is thanked for a meticulous reading of the submitted draft of the manuscript.

\section{Literature}

CHANDLER, P. 2002: Heterotricha LOEW and allied genera (Diptera: Sciaroidea): offshoots of the stem group of Mycetophilidae and/or Sciaridae? - Annales de la Société Entomologique de France (n. s.) 17: 99-123. JASCHHOF, M. 1998: Revision der „Lestremiinae“ (Diptera, Cecidomyiidae) der Holarktis. - Studia dipterologica Supplement, Halle (S.) 4: 1-552.

JASCHHOF, M. \& DIDHAM, R. K. 2002: Rangomaramidae fam. nov. from New Zealand and implications for the phylogeny of the Sciaroidea (Diptera: Bibionomorpha). - Studia dipterologica Supplement, Halle (S.) 11:1-60.

JASCHHOF, M. \& HIPPA, H. 2002: Sciaroid but not sciarid: a review of the genus Obakunea TONNOIR \& EDWARDS, with the description of two new species (Insecta: Diptera: Bibionomorpha). - Entomologische Abhandlungen, Dresden 60: 23-44.

JASCHHOF, M. \& JASCHHOF, C. 2003: Wood midges of New Zealand (Cecidomyiidae, Lestremiinae). Part I: Introductory notes and tribes Lestremiini, Strobliellini, Campylomyzini and Pteridomyini JASCHHOF trib. nov. - Studia dipterologica, Halle (S.) 10 (2003) (1): 97-132.

MATrLe, L. 1981: Description d'un Keroplatidae du Crétacé Moyen et données morphologiques et taxonomiques sur les Mycetophiloidea (Diptera). - Annales de la Société Entomologique de France (n. s.) 17:99-123.

SöLI, G. E. 1997: The adult morphology of Mycetophilidae (s. str.), with a tentative phylogeny of the family (Diptera, Sciaroidea). - Entomologica Scandinavica, Supplement 50: 5-55.

TONNOIR, A. L. \& EDWARDS, F. W. 1927: New Zealand fungus gnats (Diptera, Mycetophilidae). - Transactions of the New Zealand Institute 57: 747-878, plts 58-80.

\section{Author's address:}

\author{
Dr. MATHIAS JASCHHOF \\ University of Greifswald \\ Zoological Institute and Museum \\ Bachstrasse 11/12 \\ D-17489 Greifswald \\ Germany \\ e-mail:mjaschhof@yahoo.de
}

